\title{
Prevalence of Obesity in Patients With Type 2 Diabetes Mellitus in Yemen
}

\author{
Butheinah A. Al-Sharafi ${ }^{1,} ;$ Abdallah A. Gunaid ${ }^{1}$ \\ ${ }^{1}$ Department of Medicine, Sana’a University Medical School, Sana'a, Yemen \\ *Corresponding author: Butheinah A. Al-Sharafi, Department of Medicine, Sana’a University Medical School,Sana’a, Yemen. Tel:+96-7733733573, Fax:+96-7771213337, E-mail: balsharafi@ \\ hotmail.com
}

Received: July 18, 2013; Revised: December 29, 2013; Accepted: January 12, 2014

\begin{abstract}
Background: Obesity is common in type 2 diabetic patients in some of the Middle Eastern countries, which are amongst the countries with highest rates of diabetes mellitus and obesity.

Objectives: We conducted this study to assess the prevalence of obesity in Yemeni patients with type 2 diabetes mellitus.

Patients and Methods: Body mass index (BMI) of patients with type 2 diabetes mellitus who were 25-years-old or older was measured during their first visit to an endocrinology and diabetes clinic in Sana'a, Yemen over a 4-year period from May 2007 to May 2011.

Results: The BMI was measured in 1640 patients (721 males and 919 females) who attended the clinic. According to the measured BMI, $328(45.5 \%), 314(43.5 \%), 79(11 \%)$ of the male patients were non-obese (BMI $\left.<25 \mathrm{~kg} / \mathrm{m}^{2}\right)$, overweight (BMI $\left.25-29.9 \mathrm{~kg} / \mathrm{m}^{2}\right)$, and obese (BMI $\geq$ $30 \mathrm{~kg} / \mathrm{m}^{2}$ ), respectively. On the other hand, $256(28 \%), 369(40.0 \%)$, and $294(32 \%)$ of the female patients were non-obese $\left(\mathrm{BMI}<25 \mathrm{~kg} / \mathrm{m}^{2}\right)$, overweight (BMI $25-29.9 \mathrm{~kg} / \mathrm{m}^{2}$ ), and obese (BMI $\geq 30 \mathrm{~kg} / \mathrm{m}^{2}$ ), respectively.

Conclusions: The prevalence of obesity in patients with type 2 diabetes mellitus in Yemen is high with respect to the Yemeni population, especially in females.
\end{abstract}

Keywords:Obesity; Overweight; Type 2 Diabetes Mellitus; Body Mass Index; HbA1c

\section{Background}

Obesity is prevalent in patients with type 2 diabetes mellitus (type $2 \mathrm{DM}$ ). In some areas such as the United Kingdom, approximately $86 \%$ of patients with type 2 DM are overweight or obese (1). In Australia 53\% of patients with type 2 DM are obese and $32.8 \%$ are overweight (2). In neighboring countries like the Saudi Arabia, the prevalence of the BMI $\geq 25$ among patients with type $2 \mathrm{DM}$ is around $87.5 \%$ and females had a higher prevalence of the BMI $\geq 25(87.7 \%$ ) in contrast to males (83.1\%) (3). In Yemen with an approximate population of 23 million, the prevalence of DM is estimated to be $9.75 \%$ in individuals aged 20-years-old and older (4). This rate is lower than the prevalence in neighboring Arab countries such as Saudi Arabia (23.1\% among patients aged 7 to 80 years) (5), Bahrain (25.7\% among patients aged 20 years or older) (6), and Oman (16.1\% among patients aged 30 to 64 years) (7).

\section{Objectives}

The aim of this study was to assess the prevalence of overweight and obesity among Yemeni patients with type 2 DM aged $\geq 25$ years on their first visit to the endocrine and diabetes clinic. In addition, we aimed to reveal its association with age of the patients, and the duration of the disease.

\section{Patients and Methods}

The Yemeni patients with type 2 DM who attended a specialized diabetes and endocrinology clinic since May 2007 through May 2011 were recruited in the study. Patients of non-Yemeni origin were excluded from the study. BMI (the weight in kilogram divided by height in square meter) was calculated for all patients at the first visit. All the participants had $\geq 25$ years of age. According to the BMI, the patients were allocated into 5 groups (BMI $<19$, 1924.9, 25-29.9, 30-34.9, and BMI $\geq 35$ ). The analysis was performed on all patients admitted to the study. Continuous variables were summarized by descriptive statistics, using means and standard deviation (SD), and the difference was measured by t test. Confidence intervals (95\% CI) were of obesity in patients with diabetes was less than what was reported in other countries. Interestingly, the study showed a significant difference in the prevalence of obesity between males and females. Only $10.9 \%$ of the males were obese vs. $32 \%$ of the females. In addition, only $1.1 \%$ of males had moderate obesity in contrast to $9.7 \%$ of females. Moreover, the findings showed much lower prevalence of obesity in patients with type 2 diabetes mellitus in comparison to the neighboring countries.

Copyright (C 2014, Research Institute For Endocrine Sciences and Iran Endocrine Society; Published by Kowsar Corp. This is an open-access article distributed under the terms of the Creative Commons Attribution License, which permits unrestricted use, distribution, and reproduction in any medium, provided the original work is properly cited. 
calculated in order to indicate precision of the sample estimation, variability of the characteristics, and the degree of confidence being studied. Median values and interquartile range (IQR 25-75\%) were also used to show the central tendency; its upper and lower quartiles as a preferred measure of range were used with skewed distribution. Categorical variables were expressed as numbers and percentages and the difference was examined by the chi-square test. Pearson correlation coefficient and its $P$ value were used to assess the correlation between variables. All statistical analyses were two-sided, using a pre-specified 5\% significance level, i.e. significance was defined as $\mathrm{P}$ value $<0.05$. Analysis was performed using SPSS software, version 18.0 for windows (SPSS Inc, Chicago, Illinois, USA).

\section{Results}

A total of 1640 Yemeni patients with 25 years of age or older attended to the clinic over a four-year period. All of them were recruited in the study. The median (IQR) duration of DM was 3.0 (0.1-8.0) years and the mean du- ration was $5.0 \pm 6.0$ years ( $95 \% \mathrm{CI}: 4.65-5.27)$. The mean age of the study population was $50.3 \pm 11.5$ years, ( $96 \%$ CI: 49.7-50.9).

Most of the patients presented with recently diagnosed DM. the duration of the disease since the time of diagnosis was less than five years, five to ten years, ten to 15 years, and more than 15 years in 980 (59.7\%), 312 (19\%), 196 (12\%), and 152 (9.3\%) patients, respectively. Among the patients, 959 (58.5\%) had a BMI $\geq 25 \mathrm{~kg} / \mathrm{m}^{2}$ and 276 (28.8\%) patients were obese (BMI $\geq 30 \mathrm{~kg} / \mathrm{m}^{2}$ ).

The basic characteristics of the study population is shown in Table 1. It illustrates that both male and female patients were age-matched and had similar duration of the disease. Although males had significantly higher height and weight than females $(\mathrm{P}<0.0001)$, females were significantly heavier than males with a mean BMI of $28 \mathrm{~kg} / \mathrm{m}^{2}$ and $25.4 \mathrm{~kg} / \mathrm{m}^{2}$, respectively $(\mathrm{P}<0.001)$.

Table 2 shows sex-specific and age-specific mean BMI values of the study population. Overall, the mean BMI was significantly higher in females $\left(28 \pm 5.3 \mathrm{~kg} / \mathrm{m}^{2}\right)$ than in males $\left(25.4 \pm 3.9 \mathrm{~kg} / \mathrm{m}^{2}\right)(\mathrm{P}<0.001)$.

\begin{tabular}{|c|c|c|c|}
\hline Variables & Male, $(n=721)$ & Female $(n=919)$ & PValue \\
\hline Age, $y$ & & & NS \\
\hline mean \pm SD & $50.3(12.5)$ & $50.7(10.7)$ & \\
\hline $95 \% \mathrm{CI}^{\mathrm{a}}$ of mean & $49.4-51.2$ & $50-51.3$ & \\
\hline $\operatorname{Median}\left(\mathrm{IQR}^{\mathrm{a}}\right)$ & $50(41-60)$ & $50(45-60)$ & \\
\hline Weight, kg & & & $<0.001$ \\
\hline mean \pm SD & $69.2(12.4)$ & $64.7(12.9)$ & \\
\hline $95 \% \mathrm{CI}$ of mean & $68.3-70.1$ & 63.9-65.6 & \\
\hline Median (IQR) & $68.9(60-76.5)$ & $63(56.3-72)$ & \\
\hline Height, cm & & & $<0.001$ \\
\hline mean \pm SD & $164.8(6.8)$ & $152(6.7)$ & \\
\hline $95 \% \mathrm{CI}$ of mean & $164.3-165.3$ & $151.5-152.3$ & \\
\hline Median (IQR) & $165(160-169)$ & $152(148-156)$ & \\
\hline BMI, $\mathrm{kg} / \mathrm{m}^{2}$ & & & $<0.001$ \\
\hline mean \pm SD & $25.4(3.9)$ & $28(5.3)$ & \\
\hline $95 \% \mathrm{CI}$ of mean & $25.1-25.7$ & $27.7-28.4$ & \\
\hline Median (IQR) & $25.3(22.7-27.9)$ & $27.6(24.4-31)$ & \\
\hline Duration of diabetes & & & NS \\
\hline mean \pm SD & $4.8(6.2)$ & $5.3(6.1)$ & \\
\hline $95 \%$ CI of Mean & $4.3-5.2$ & $4.9-5.7$ & \\
\hline Median (IQR) & $2.0(0.0-7.0)$ & $3.0(0.3-8.0)$ & \\
\hline
\end{tabular}

\footnotetext{
a Abbreviation: $\mathrm{Cl}$, Confidence interval; IQR, interquartile range.
} 
Al-Sharafi BA et al.

\begin{tabular}{|c|c|c|c|c|c|c|}
\hline \multirow[t]{2}{*}{ Age range, y } & \multicolumn{3}{|c|}{ Male } & \multicolumn{3}{|c|}{ Female } \\
\hline & No. & $\mathrm{BMI}^{\mathrm{a}}$, Mean $\pm \mathrm{SD}$ & $\mathrm{SE}^{\mathrm{a}}$ & No. & BMI $^{\mathrm{a}}$, Mean \pm SD & SE \\
\hline Overall (total sample) & 721 & $25.4 \pm 3.9$ & 0.14 & 919 & $28 \pm 5.3$ & 0.18 \\
\hline $25-34$ & 78 & $25.9 \pm 3.9$ & 0.44 & 63 & $27.6 \pm 6.0$ & 0.8 \\
\hline $35-44$ & 144 & $26.1 \pm 4.4$ & 0.37 & 154 & $28.9 \pm 5.9$ & 0.47 \\
\hline $45-54$ & 217 & $25.4 \pm 3.5$ & 0.24 & 326 & $28.4 \pm 5.3$ & 0.29 \\
\hline $55-64$ & 174 & $25.4 \pm 3.6$ & 0.27 & 285 & $27.6 \pm 4.6$ & 0.27 \\
\hline $65+$ & 108 & $24.2 \pm 4.0$ & 0.38 & 91 & $26.8 \pm 5.7$ & 0.6 \\
\hline
\end{tabular}

${ }^{a}$ Abbreviations: BMI, body mass index; SE, standard error

There was a significant difference between the mean BMI for females and males in all age groups. The peak differnce in the mean BMI between females and males was in those aged 45-54. There were significant sex differences with regard to the BMI distributions in patients with type 2 DM. In patients with a low or normal BMI, we found a male preponderance. Among the group with a BMI < 19 , there were 29 (4.0\%) males out of 721 and $16(1.7 \%)$ out of 919 were females (Yates corrected $\mathrm{X}^{2}=7.0, \mathrm{P}=0.008$ ). Among those with normal weight (BMI, 19-24.9 kg/m²), there were 299 (41.5\%) out of 721 males and 240 (26.1\%) out of 919 females (Yates corrected $\mathrm{X}^{2}=42.5, \mathrm{P}<0.0001$ ). In the overweight group (BMI of 25-29.9 kg/m²), 314 (43.6\%) out of 721 were males and 369 (40.2\%) out of 919 were females (Yates corrected $\mathrm{X}^{2}=1.8, \mathrm{P}=0.18$ ). In the group with mild obesity (BMI of 30-34.9 kg/m²), there were 205 (22.3\%) out of 919 females 71 (9.8\%) out of 721 males (Yates corrected $\left.\mathrm{X}^{2}=43.9, \mathrm{P}<0.0001\right)$. In the group with moderate obesity (BMI $\geq 35$ ), we also found a much higher rate of obesity among the females than males with the frequency of 89 (9.7\%) out of 919 and 8 (1.1\%) out of 721 patients, respectively (Yates corrected $\mathrm{X}^{2}=51.9, \mathrm{P}<0.0001$ ).

In order to have further insight into the association among different variables, we computed Pearson correlation coefficient ( $r$ ) for exploring the association between BMI and each patient's age and duration of DM. We also tested the association between duration of DM and glycemic control expressed as HbA1c levels. There was a significant inverse correlation between BMI and age ( $\mathrm{r}=$ -0.100, 2-tailed $\mathrm{P}=0.01$ ), between BMI and duration of DM $(\mathrm{r}=-0.067,2$-tailed $\mathrm{P}=0.01)$ These results declared that the BMI values tended to be significantly lower with advanced age and increased duration of diabetes.

\section{Discussion}

In this study, the prevalence of BMI $\geq 25 \mathrm{~kg} / \mathrm{m}^{2}$ in patients with type 2 DM was approximately $58.5 \%$ and $28.8 \%$ of them were obese (BMI $\geq 30 \mathrm{~kg} / \mathrm{m}^{2}$ ). The sex-specific and age-specific mean BMI values were significantly higher in females than in males across different age groups with the peak difference between 45 to 54 years of age. Most of our patients in our study were recently diagnosed.
With the increasing prevalence of obesity, DM has become a growing problem worldwide. Both DM and obesity are multifactorial diseases of considerable heterogeneity (8). The Eastern Mediterranean region had one of the highest prevalence of obesity worldwide (9). This is particularly true for countries in the region, like Saudi Arabia, where obesity prevalence is $23 \%$ in males and $36.4 \%$ in females and Egypt, where obesity prevalence is $22 \%$ in males and $48 \%$ in females (10). On contrary, in less wealthy countries like Sudan and Yemen, the prevalence of obesity is much lower with $1.5 \%$ in males and $6.5 \%$ in females in Sudan (ages 25-64) (10) and 2.5\% in males and $12.4 \%$ in females in Yemen aged 20 and older (11). moreover, five Persian Gulf countries are among the countries with the highest prevalence of DM in the world including neighboring countries to Yemen as Saudi Arabia and Oman (among those aged 20-79) (12). In our study, patients with DM who were overweight or obese accounted for more than $64 \%$ of the total investigated population with DM. This figure was higher than the findings of a previous study in Yemen that overweight and obesity accounted only for $26.2 \%$ of patients with type 2 DM aged 20-65 (13). The worldwide data Analysis concerning the association between BMI and both morbidity and mortality suggested that the association of BMI with most diseases was rather continuous (14) and generally, women had a higher mean BMI than men (15). Therefore, using the mean BMI changed the usual categorical analysis based on the rates of overweight and obesity. Our data indicated that at all ages, females had higher mean BMI than males, and that the overall mean BMI was significantly higher in females than in males (28 vs. 25.4). These results were also higher than the previously published mean BMI of participants from an urban community in Yemen (23.9 and. 21.8 in females and males, respectively) (16). In our study, the prevalence rate of obesity (BMI $\geq$ $\left.30 \mathrm{~kg} / \mathrm{m}^{2}\right)$ in females was three times higher than males with type 2 DM (32\% vs. 11\%). This female-male difference was even higher than the rate reported from Saudi Arabia (87.7\% vs. 83.1\%)(3). Despite the majority of women denied any special effort when questioned about exercise, the validity of self-reported levels of physical activity was not always reliable (17). Therefore, further studies have to be 
done to assess the risk factors associated with a higher prevalence of obesity among female patients with DM in Yemen. More DM health education has to be provided to our patients, as the majority of them did not know the risk factors associated with the development of type $2 \mathrm{DM}$ and obesity.

In this study, in the case of severe obesity (BMI $\geq 35$ $\mathrm{kg} / \mathrm{m}^{2}$ ), prevalence rate in women was about nine times higher than in males (9.7\% and $1.1 \%$, respectively), which seemed to be higher than any female-male difference in neighboring countries. Many factors have been shown to be associated with an increased risk of obesity and DM such as high intake of sugar-sweetened beverages (16, 18). In some neighboring countries, factors such as unemployment and marriage were associated with weight gain in females (19). In Saudi Arabia, working women had a lower rate of obesity than non-working ones (20); moreover, the prevalence of inactivity among people was very high (approximately 96.1\%) with a significantly higher rate of inactivity among females in comparison to males. Obesity decreased with the level of education and increased with the age, especially in males (21).

DM and obesity has already become a worldwide epidemic with significant health and economic burdens (21). The best way to overcome this epidemic is screening for early detection, prevention, and early management of obesity before the development of type 2 DM, especially in younger individuals (22). Physical activity should be encouraged in our patients with DM, especially in females. The American Heart Association and the American Diabetes Association recommends carrying out at least 150 minutes of moderate-intensive aerobic activity, or at least 90 minutes of vigorous aerobic exercise per week (23)

Diet control still remains the cornerstone in the treatment of DM and most patients find this area of self-management difficult (24). It has been shown that group education for patients with type 2 DM by a diabetes specialist nurse and dietitian had better results than those receiving the usual clinic care in both weight loss and diabetes control (25). The majority of the patients claimed that they had been following what they considered as a diabetic diet. During questioning, they had many misunderstanding concerning which diet should have been prescribed. Most of the times, the diet education that they had received was prescription of a friend or a relatives who had no diabetes education or in the best situations, in a prescription from a physician. Dietary education should be emphasized in these patients. Although compliance and adherence to diet is poor among diabetics, dietary counseling has been shown to improve dietary practices in patients with type 2 DM (26). Education on the complications of obesity and DM is very important in Yemeni patients since the majority of the patients have not visited a diabetes educator or dietitian due to the low number of these professional workers. Hence, educating the patients on diet and exercise and their importance in diabetes control remains the responsibility of the physicians.

Our study had some limitations since it was a single center study with most of the patients from Sana'a and the surrounding regions. Larger studies covering the different regions of Yemen should be conducted to see if similar differences in obesity in male and female patients with DM are present. In addition, further studies have to be conducted to assess the factors causing obesity in these patients and if possible, slowing down the increasing rate of obesity and associated metabolic diseases.

In conclusion, the overweightness and obesity (high BMI) were prevalent in patients with type 2 DM in Yemen, with a higher frequency in females than in males. Moreover, the mean BMI, as a continuous variable associated with morbidity and mortality, was significantly higher in females than in males at different age groups. The finding of poor glycemic control among the majority of patients was another alarming sign of low quality diabetes care in this country. We recommend improving the standards of diabetes health care in Yemen at the primary and critical care levels in order to reduce the burden attributable to the DM in the Yemen.

\section{Acknowledgements}

The authors expressed their thanks to Mr. Mohamed AlKobati for his statistical advice.

\section{Authors' Contribution}

Study design, examining the patients, data collection and writing the manuscript: Dr. Butheinah Al-Sharafi's; Study design, planning, supervising statistical analysis of the data, and participation in writing the manuscript: Prof. Abdullah Gunaid's.

\section{Financial Disclosure}

The authors had no financial interest to disclose.

\section{Funding/Support}

No funding support was provided.

\section{References}

1. Daousi C, Casson IF, Gill GV, MacFarlane IA, Wilding JP, Pinkney $\mathrm{JH}$. Prevalence of obesity in type 2 diabetes in secondary care: association with cardiovascular risk factors. Postgrad Med J. 2006;82(966):280-4.

2. Thomas MC, Zimmet P, Shaw JE. Identification of obesity in patients with type 2 diabetes from Australian primary care: the NEFRON-5 study. Diabetes Care. 2006;29(12):2723-5.

3. Alqurashi KA, Aljabri KS, Bokhari SA. Prevalence of diabetes mellitus in a Saudi community. Ann Saudi Med. 2011;31(1):19-23.

4. Gunaid AA. Prevalence of known diabetes and hypertension in the Republic of Yemen. East Mediterr Health J. 2002;8(2-3):374-85.

5. Al-Daghri NM, Al-Attas OS, Alokail MS, Alkharfy KM, Yousef M, Sabico SL, et al. Diabetes mellitus type 2 and other chronic noncommunicable diseases in the central region, Saudi Arabia (Ri- 
yadh cohort 2): a decade of an epidemic. BMC Med. 2011;9:76.

6. Hamadeh RR. Noncommunicable diseases among the Bahraini population: a review. East Mediterr Health J. 2000;6(5-6):1091-7.

7. Al-Lawati JA, Al Riyami AM, Mohammed AJ, Jousilahti P. Increasing prevalence of diabetes mellitus in Oman. Diabet Med. 2002;19(11):954-7.

8. Zimmet P, Alberti KG, Shaw J. Global and societal implications of the diabetes epidemic. Nature. 2001;414(6865):782-7.

9. Musaiger AO. Overweight and obesity in eastern mediterranean region: prevalence and possible causes. J Obes. 2011;2011:407237.

10. Global Infobase [database on the Internet].. Available from: https:/ apps.who.int/infobase/.

11. Gunaid AA. Obesity, overweight and underweight among adults in an urban community in Yemen. East Mediterr Health J. 2012;18(12):1187-93.

12. Top 10 countries in diabetes prevalence in the world. Diabetes dataidf diabetes atlas 4th edition.. Available from: http://www.idf.org/ media/press-materials/diabetes-data.

13. Gunaid AA, El Khally FM, Hassan NA, Mukhtar el D. Demographic and clinical features of diabetes mellitus in 1095 Yemeni patients. Ann Saudi Med.1997;17(4):402-9.

14. Finucane MM, Stevens GA, Cowan MJ, Danaei G, Lin JK, Paciorek CJ, et al. National, regional, and global trends in body-mass index since 1980: systematic analysis of health examination surveys and epidemiological studies with 960 country-years and 9.1 million participants. Lancet. 2011;377(9765):557-67.

15. James WPT, Jackson-Leach R, Mhurchu CN, Kalamara E, Shayeghi $\mathrm{M}$, Rigby NJ, et al. Overweight and obesity (high body mass index). In: Ezzati M et al. editor. Comparative quantification of health risks: global nd regional burden of disease attributable to major risk factors.. Geneva: World Health Organization; 2004. pp. 497-596.

16. Schulze MB, Manson JE, Ludwig DS, Colditz GA, Stampfer MJ Willett WC, et al. Sugar-sweetened beverages, weight gain, and incidence of type 2 diabetes in young and middle-aged women. JAMA. 2004;292(8):927-34.
17. Gunaid AA, Assabri AM. Prevalence of type 2 diabetes and other cardiovascular risk factors in a semirural area in Yemen. East Mediterr Health J. 2008;14(1):42-56.

18. Qi Q, Chu AY, Kang JH, Jensen MK, Curhan GC, Pasquale LR, et al. Sugar-sweetened beverages and genetic risk of obesity. $N$ Engl J Med. 2012;367(15):1387-96.

19. Ahmad MN, Tukan SK, Takruri HR. Obesity and overweight in young adult females of Northern Badia of Jordan. Malaysian Journal of Nutrition. 2006;12(2):157-66.

20. Musaiger AO, Al-Ahdal E. Social and dietary factors associated with obesity among women in Saudi Arabia. In: Musaiger AO editor. Obesity in the Arab World.. Bahrain: Arab Center for Nutrition; 2010.

21. Al-Nozha MM, Al-Hazzaa HM, Arafah MR, Al-Khadra A, Al-Mazrou YY, Al-Maatouq MA, et al. Prevalence of physical activity and inactivity among Saudis aged 30-70 years. A population-based crosssectional study. Saudi Med J. 2007;28(4):559-68.

22. Farag YM, Gaballa MR. Diabesity: an overview of a rising epidemic. Nephrol Dial Transplant. 2011;26(1):28-35.

23. Buse JB, Ginsberg HN, Bakris GL, Clark NG, Costa F, Eckel R, et al. Primary prevention of cardiovascular diseases in people with diabetes mellitus: a scientific statement from the American Heart Association and the American Diabetes Association. Circulation. 2007;115(1):114-26.

24. Al-Kaabi J, Al-Maskari F, Saadi H, Afandi B, Parkar H, Nagelkerke N. Assessment of dietary practice among diabetic patients in the United arab emirates. Rev Diabet Stud. 2008;5(2):110-5.

25. Heller SR, Clarke P, Daly H, Davis I, McCulloch DK, Allison SP, et al. Group education for obese patients with type 2 diabetes: greater success at less cost. Diabet Med.1988;5(6):552-6.

26. Abioye-Kuteyi EA, Ojofeitimi EO, Ijadunola KT, Fasanu AO. Assessment of dietary knowledge, practices and control in type 2 diabetes in a Nigerian teaching hospital. Niger JMed. 2005;14(1):58-64. 